\title{
Measuring the Impact of Fiscal Decentralization on Economic Growth and Income Inequality using the Heuristic Network
}

\author{
Juliansyah Roy, Diana Lestari, Arfiah Busari
}

\begin{abstract}
To achieve regional economic growth, the role of regional budgets is very important. In this regard, the utilization of regional economic and financial resources is an important factor in supporting the implementation of the fiscal decentralization system in the area. The implementation of fiscal decentralization in Indonesia is marked by the process of transferring financial resources to regions in significant amounts. In the last five years (2011-2015), the proportion of balancing funds to total regional income nationally reached an average of $73 \%$. Despite the huge spike in decentralization policies, the implementation of fiscal decentralization in East Kalimantan Province, one of Indonesia's provinces, till now has not been able to bring about improving the welfare of local communities. In reality, there is still income inequality, although still relatively low in East Kalimantan Province. This study performs to measure the impact of fiscal decentralization on economic growth and income inequality in East Kalimantan Indonesia. The hypothesis in this study is that fiscal decentralization negatively affects income inequality directly or indirectly through economic growth in East Kalimantan Indonesia. The aim of this study is how to use the heuristic network to prove this hypothesis.
\end{abstract}

Keywords- fiscal decentralization, economic growth, income inequality, heuristic network

\section{INTRODUCTION}

Until now, fiscal decentralization and regional autonomy are always interesting topics to discuss. This is because the study of fiscal decentralization is not only an economic aspect, but is closely related to other dimensions such as politics, administrative, and geographical. Moreover, the results of fiscal decentralization studies often do not produce the same conclusions among researchers and enthusiasts of decentralization. There is a clash of opinions with each side having a logical argument and empirically proving it. From a development point of view, decentralization is not only aimed at improving fiscal capacity and efficiency, but also on improving the institutional quality at the local level to support economic growth. This is stated by the study that has been done in [1]. The results of this study confirm that the level of fiscal decentralization is a major determinant of the state's fiscal efficiency. One study of the impact of fiscal

Revised Manuscript Received on April 19, 2019.

Juliansyah Roy, Department of Economic Study, Mulawarman University, East Kalimantan, Indonesia. (E-Mail: jlnsyh_roy@yahoo.com)

Diana Lestari, Assistant Professor, Department of Management Studies, KLHBS, Hyderabad, R.R, Telangana, India (E-Mail: diana_lestari82@yaoo.co.id)

Arfiah Busari, Professor, Department of ECE, Sreenidhi Institute of Science \& Technology, Hyderabad, India (E-Mail: arfiahbusari@gmail.com) decentralization on economic growth that has been done in [2] shows that fiscal decentralization can lead to significant long-term economic growth (especially significant for income decentralization), but in the short run, this causes a decline in economic growth. To achieve regional economic growth, the role of regional budgets is very important. Through local budgets, local governments can allocate a portion of their revenues to improve public services. The budgeting mechanism in this area involves the stakeholders in determining the priority and size of the budget ceilings required in the financing of public services. In this regard, the utilization of regional economic and financial resources is an important factor in supporting the implementation of the fiscal decentralization system in the area. However, the implementation of fiscal decentralization can lead to fiscal disparities and unequal utilization of factors of production (economic resources) that exist in the area. This inequality can lead to uneven fiscal capacity between regions, so that regional financial independence becomes disrupted in supporting the achievement of regional economic growth. This has been studied in [3]. In another study that has been done in (1) shows that fiscal decentralization is increasing when equipped with good institutional structures in terms of low corruption in government institutions, legislation, high bureaucratic quality and democratic accountability. Therefore, decentralization can be an increase in growth if macroeconomic stability and the quality of government institutions exceed the critical levels (economic resources) that exist in the region. This inequality can lead to uneven fiscal capacity between regions, so that regional financial independence is disrupted in supporting the achievement of regional economic growth [4].

The implementation of fiscal decentralization in Indonesia is marked by the process of transferring financial resources to regions in significant amounts. In the last five years (2011-2015), the proportion of balancing funds to total regional income nationally reached an average of $73 \%$. From these figures, it is clear that the regions are still dependent on the balancing funds to carry out their various development programs and activities. As it is the largest component in the allocation of transfers to regions, balancing funds have a very important role in regional finance, especially in supporting the implementation of fiscal decentralization and regional autonomy. The government continues to make a continuous improvement on the mechanism of channelling transfers to the regions. 
There are many studies on the effectiveness of fiscal decentralization policies, one of which is in [5] which measures and determines the effectiveness of fiscal decentralization. Despite the huge spike in decentralization policies, the implementation of fiscal decentralization in East Kalimantan Province, one of Indonesia's provinces, till now has not been able to bring about improving the welfare of local communities. In reality, there is still income inequality, although still relatively low in East Kalimantan Province. The income inequality can be interpreted as the difference in economic prosperity between the rich and the poor. This is reflected in the difference in income. As a result of the difference it will be seen the gap between the rich will get richer and otherwise the poor will get worse. One of study that has been conducted in [6] shows that educational; wealth, and also the employment sector are significant contributors to income inequality in Indonesia. These findings suggest that any policy aimed at reducing unequal access to education and finance is important to improve future income inequality.

Other studies that have been done in [7] have considered how education and globalization affect the income inequality in Asia, with uneven panel data. The results of this study indicate that a higher education levels achieved by people aged 15 and over have improved the distribution of income in Asia, while education inequality, as measured by the Gini education index, has a negative impact on income distribution. The various transmission mechanisms and drivers of increased income inequality are identified and the possibility of a forward-looking development policy to reduce income inequality is given. This has been studied in [8]. The study findings that have been made in [9] show that decentralization initially hampered but ultimately in creased accountability and political and civil freedom, in line with the positive correlation hypothesis between larger fiscal autonomy and inclusive participatory government. The impact of fiscal decentralization on income inequality depends on local government financial resources, i.e. intergovernmental transfers may have a role in equal distribution of income, and provide empirical support for the validity of the Kuznets hypothesis in which there is a nonlinear relationship between the rate of economic development and income inequality [10].

There are so many methods and techniques to measure the impact of a variable on other variables and/or to measure comparative performance in terms of technical efficiency. One of them is descriptive analysis, Pearson correlation test, regression test used to test the correlation of data pattern that has been modelled using multiple linear models [11]. Random effects of GLS (Generalized Least Square) regression and G2SLS (Generalized Two-Stage Least Square) and Kuznets hypothesis have also been used to measure the impact of fiscal decentralization on poverty and income inequality in [12]. Parametric model (using simple OLS (Ordinary Least Square)) and non-parametric model (using DEA (Data Envelopment Analysis)) have also been used to measure comparative performance in terms of technical efficiency [1].

This study proposes the use of Heuristic Networks to measure the impact of fiscal decentralization on economic growth and income inequality in East Kalimantan -
Indonesia. The hypothesis in this study is that fiscal decentralization negatively affects income inequality directly or indirectly through economic growth in East Kalimantan - Indonesia. The aim of this study is to prove the hypothesis.

\section{METHODS}

\subsection{Economic Growth and Income Inequality}

Economic growth is the process of changing the economic conditions of a country/region on a continuous basis to a better state for a certain period. Economic growth can be interpreted also as a process of increasing the production capacity of an economy which is realized in the form of an increase in national income. The existence of economic growth is an indication of the success of economic development in people's lives. Economists define economic growth as an increase in GDP / GRDP, regardless of whether the increase is greater or less than the rate of population growth, or whether or not a change economic structure. The most important components of economic growth are capital accumulation, population growth, and technological progress. Economic growth is measured by comparing the current GDP / GRDP with the previous year. In relation to regional economic growth, this can be stated as:

$$
\operatorname{Growth}(t)=\frac{\operatorname{GRDP}(t)-\operatorname{GRDP}(t-1)}{\operatorname{GRDP}(t-1)} \times 100
$$

Where Growth $(t), \operatorname{GRDP}(t)$ and $\operatorname{GRDP}(t-1)$ are economic growth in current year, GRDP in current year and GRDP in previous year, respectively.

The income inequality is the difference in the amount of income received by society, resulting in greater income disparities among groups within the community. As a result of the difference it will be seen the gap of the rich will get richer and otherwise the poor will get worse. Indicators to determine inequality and income gap can be done with Lorenz curve and GINI coefficients expressed by the following formula [8]:

$$
\operatorname{GINI}(t)=\frac{\sum_{j=1}^{N} \sum_{k=1}^{N}\left|y_{j}-y_{k}\right| P_{j} P_{k}}{2 \bar{Y} \sum_{i=1}^{N} P_{i}}
$$

Where $y_{i}$ is country's $i$ 's relevant measure of income and/or consumption (or indicator of interest), and $P_{i}$ is country's $i$ 's population. $\bar{Y}$ is the total average income and/or consumption weighted by population which expressed by:

$$
\bar{Y}=\frac{\sum_{i=1}^{N} y_{i} P_{i}}{\sum_{i=1}^{N} P_{i}}
$$

The Gini coefficient will give a value between 0 and 1 , with 0 denoting the perfect equation and 1 indicating perfect inequality. 
Fiscal decentralization is a vital issue in the academic discipline of public finance for its effects on the efficiency of public sector and economic growth. Theoretically, fiscal independence at sub-national level leads to higher per capita output and higher rates of growth by enhancing economic efficiency. Fiscal decentralization promotes economic growth by transmitting spending authority to better- equipped local governments to effectively meet country and regional demands. The benefits of fiscal decentralization also have some potential risks that can adversely affect economic growth and development [4]. Conceptually, the form of functional relationships of the effects of fiscal decentralization on economic growth and income inequality is shown in Fig. 1.

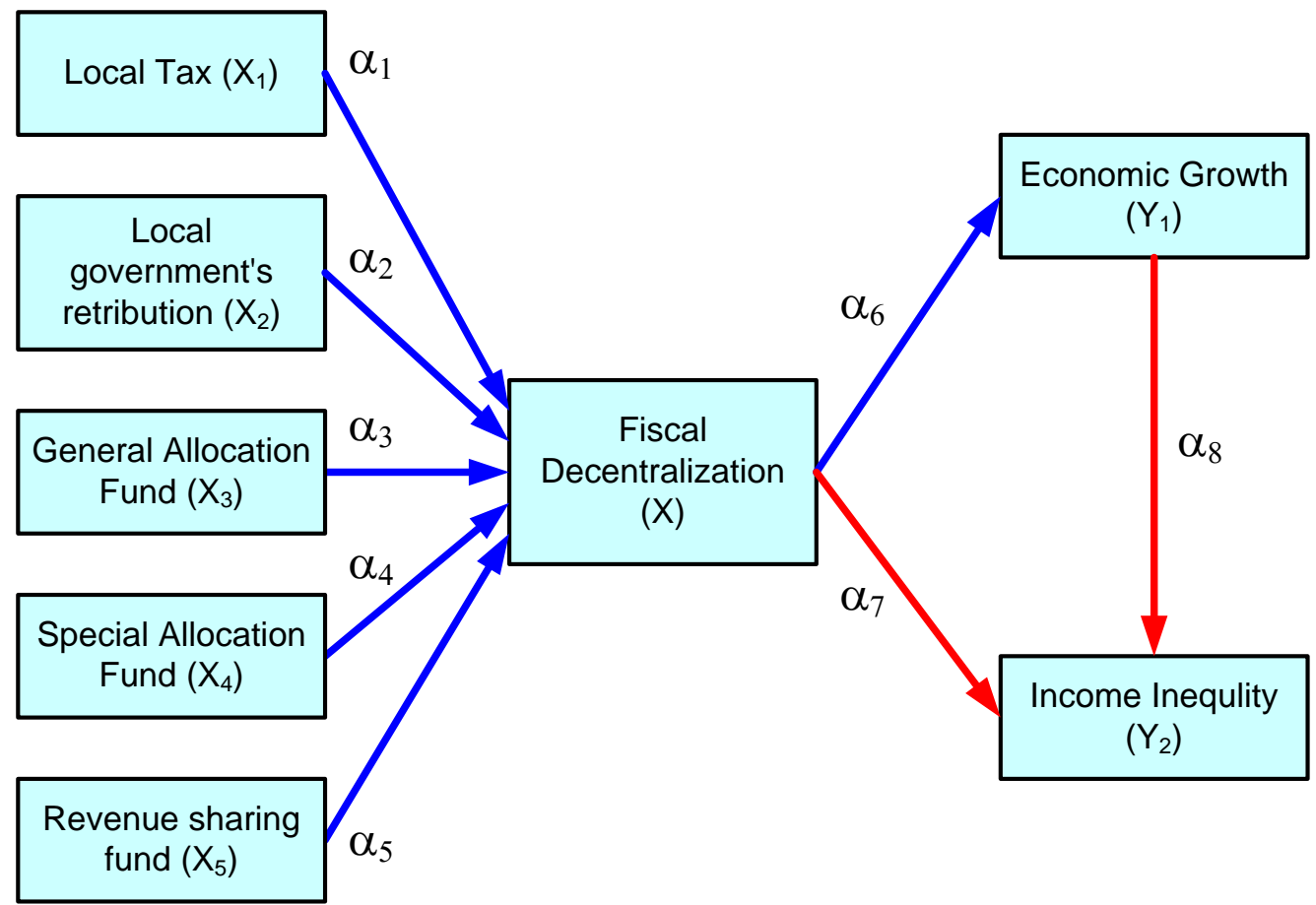

Figure 1. The form of functional relationships of the effects of fiscal decentralization on economic growth and income inequality

Mathematically, the model of the structural equation is expressed by:

$$
\begin{gathered}
X=\alpha_{1} X_{1}+\alpha_{2} X_{2}+\alpha_{3} X_{3}+\alpha_{4} X_{4}+\alpha_{5} X_{5}+e_{1} \\
Y_{1}=\alpha_{6} X+e_{2} \\
Y_{2}=\alpha_{7} X+\alpha_{8} Y_{1}+e_{3}
\end{gathered}
$$

Where $Y_{1}$ and $Y_{2}$ are the economic growth and income inequality, respectively, $X_{1} \ldots X_{5}$ are the variables of fiscal decentralization, $\alpha_{1} \ldots \alpha_{8}$ are partial coefficients of $X$, and $Y$, and $e_{1} \ldots e_{3}$ are estimated error. Referring to Eq. (5), $X$ is independent variable, whereas $Y_{1}$ is dependent variable. Referring to Eq. (6), $X$ and $Y_{1}$ are independent variables, whereas $Y_{2}$ is dependent variable.

\subsection{Heuristic Network}

Unlike algorithms, heuristics are problem-solving, learning, or discovery approaches that use practical methods that are not guaranteed to be optimal or perfect, but significant enough to achieve goals [13]. In other words, brought to logical boundaries, heuristic is a rule of thumb. The process of heuristic solutions depends on intuitive or empirical rules, which, if applied to the problem, provide one or more solutions [14]. Referring to Eq. (4) - (6), there are many method to obtained all partial coefficients and estimated errors. Some of them are OLS and GARCH (Generalized Auto Regressive Conditional Heterokedasticity). The substitution of Eq. (4) into Eq. (5) is denoted by:

$$
\begin{gathered}
Y_{1}=\alpha_{6}\left(\alpha_{1} X_{1}+\alpha_{2} X_{2}+\alpha_{3} X_{3}+\alpha_{4} X_{4}+\alpha_{5} X_{5}\right. \\
\left.+e_{1}\right)+e_{2} \\
Y_{1}=a_{1} X_{1}+a_{2} X_{2}+a_{3} X_{3}+a_{4} X_{4}+a_{5} X_{5}+\mu
\end{gathered}
$$

Where $a_{1} \ldots a_{5}$ and $\mu$ are the new partial coefficients, and estimated error of $Y_{1}$, respectively.

If each variable $X$ is considered to contribute an estimated error then Eq. (7) can be expressed by:

$$
\begin{array}{r}
Y_{1}=\left(a_{1} X_{1}+\mu_{1}\right)+\left(a_{2} X_{2}+\mu_{2}\right)+\left(a_{3} X_{3}+\mu_{3}\right) \\
+\left(a_{4} X_{4}+\mu_{4}\right)+\left(a_{5} X_{5}+\mu_{5}\right)
\end{array}
$$

If the estimated contribution of each variable error $X$ is considered to be derived from the residual correlation between variable $X$ and all other variables, then it can be expressed:

$$
\begin{aligned}
& Y_{1}=c_{1} f\left(a_{11} X_{1}\right.\left.+a_{12} \cdot f\left(R_{1}\right)\right) \\
&+c_{2} \cdot f\left(a_{21} X_{2}+a_{22} \cdot f\left(R_{2}\right)\right) \\
&+c_{3} \cdot f\left(a_{31} X_{3}+a_{32} \cdot f\left(R_{3}\right)\right) \\
&+c_{4} \cdot f\left(a_{41} X_{4}+a_{42} \cdot f\left(R_{4}\right)\right) \\
&+c_{5} \cdot f\left(a_{51} X_{5}+a_{52} \cdot f\left(R_{5}\right)\right)+Z \\
& R_{1}=w_{12} X_{2}+w_{13} X_{3}+w_{14} X_{4}+w_{15} X_{5} \\
& R_{2}=w_{21} X_{1}+w_{23} X_{3}+w_{34} X_{4}+w_{35} X_{5} \\
& R_{3}=w_{31} X_{1}+w_{32} X_{2}+w_{34} X_{4}+w_{35} X_{5} \\
& R_{4}=w_{41} X_{1}+w_{42} X_{2}+w_{43} X_{3}+w_{45} X_{5} \\
& R_{5}=w_{51} X_{1}+w_{52} X_{2}+w_{53} X_{3}+w_{54} X_{4}
\end{aligned}
$$


Where $a_{11} \ldots a_{51}$ and $a_{12} \ldots a_{52}$ are the partial coefficient of each variable $X$, and partial coefficient of their residual correlation, respectively, $w_{12} \ldots w_{54}$ are the weight of each other variables, $c_{1} \ldots c_{5}$ are main coefficients of each variable $X$, and $f()$ is a logistics function that guarantees the sum of all data multiplications with each weighting within acceptable data ranges. $Z$ is control variable. If all input variables are independent and all data is normalized such that they are in range $\{0 \ldots 1\}$ then initial value $Z=-1$. In compact form can be stated by:

$$
\begin{aligned}
& {\left[\begin{array}{l}
R_{1} \\
R_{2} \\
R_{3} \\
R_{4} \\
R_{5}
\end{array}\right]=\left[\begin{array}{ccccc}
0 & w_{12} & w_{13} & w_{14} & w_{15} \\
w_{21} & 0 & w_{23} & w_{24} & w_{25} \\
w_{31} & w_{32} & 0 & w_{34} & w_{35} \\
w_{41} & w_{42} & w_{43} & 0 & w_{45} \\
w_{51} & w_{52} & w_{53} & w_{54} & 0
\end{array}\right] *\left[\begin{array}{l}
X_{1} \\
X_{2} \\
X_{3} \\
X_{4} \\
X_{5}
\end{array}\right]} \\
& {\left[\begin{array}{l}
Y_{11} \\
Y_{12} \\
Y_{13} \\
Y_{14} \\
Y_{15}
\end{array}\right]=f\left(\left[\begin{array}{l}
a_{11} \\
a_{31} \\
a_{41} \\
a_{51}
\end{array}\right] \cdot\left[\begin{array}{l}
X_{1} \\
X_{2} \\
X_{3} \\
X_{4} \\
X_{5}
\end{array}\right]+\left[\begin{array}{l}
a_{12} \\
a_{22} \\
a_{32} \\
a_{42} \\
a_{52}
\end{array}\right] * f\left(\left[\begin{array}{l}
R_{1} \\
R_{2} \\
R_{3} \\
R_{4} \\
R_{5}
\end{array}\right]\right)\right)}
\end{aligned}
$$

$$
Y_{1}=\left[\begin{array}{l}
c_{1} \\
c_{2} \\
c_{3} \\
c_{4} \\
c_{5}
\end{array}\right] \cdot *\left[\begin{array}{l}
Y_{11} \\
Y_{12} \\
Y_{13} \\
Y_{14} \\
Y_{15}
\end{array}\right]+Z
$$

Eq. (11) - (13) can be described by using heuristic network as shown in Fig. 2. If actual value denoted by $Y_{1}$ and output heuristic network denoted by $\bar{Y}_{1}$ then the error network expressed by:

$$
e=Y_{1}-\bar{Y}_{1}
$$

The error function used is SSE (Sum Squared Error) which is expressed by:

$$
S S E=\frac{1}{2} \sum_{i=1}^{K}\left(Y_{1}(i)-\bar{Y}_{1}(i)\right)^{2}=\frac{1}{2} \sum_{i=1}^{K}(e(i))^{2}
$$

Where $K$ is the number of train data.

The Heuristic Network is built to optimize all network weights in such a way so that $S S E \rightarrow 0$ through training process.

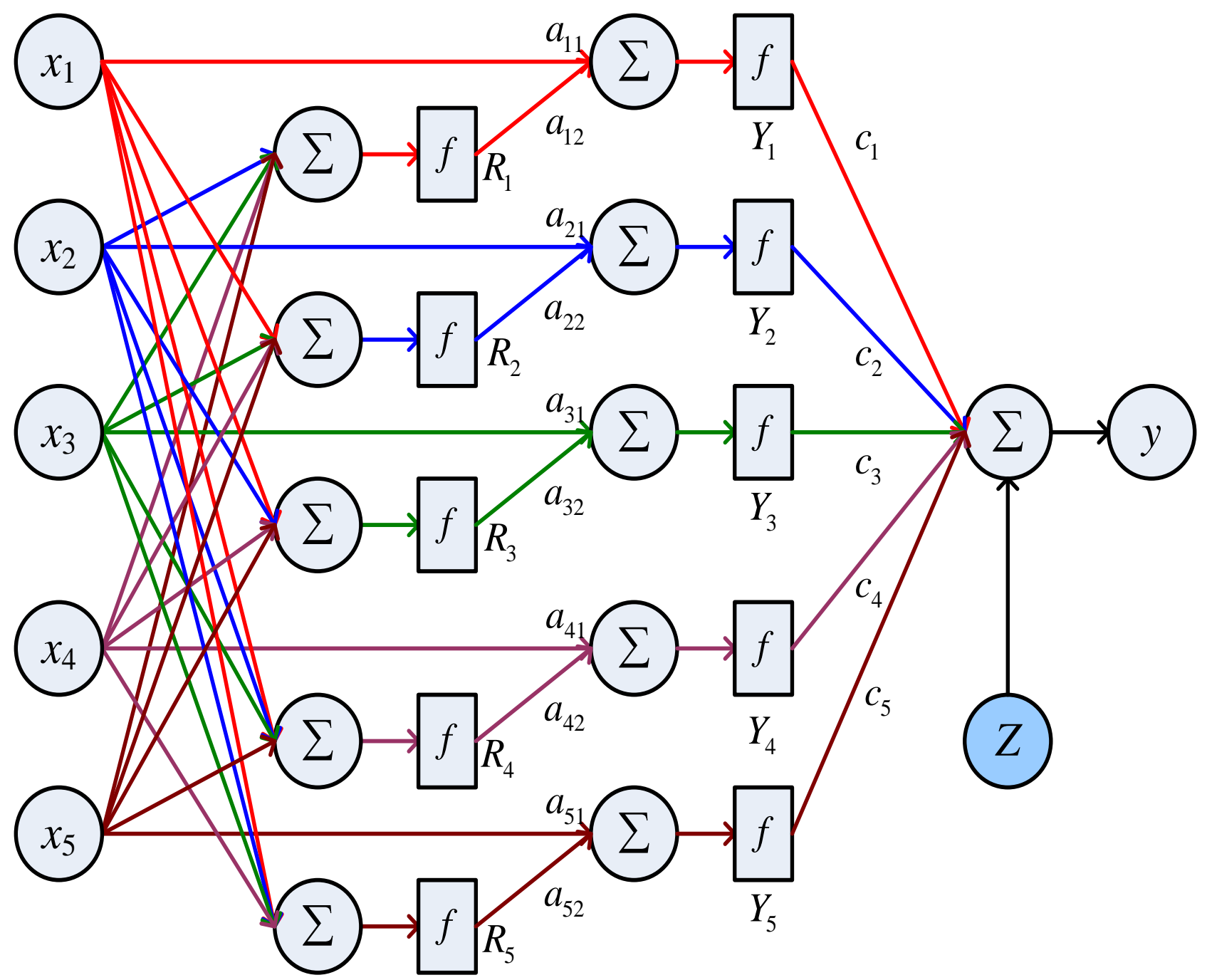

Figure 2. Heuristic Network 
Weighted adjustment is done by dividing network error based on the weighting proportion. Referring to Fig. 2, then the division of network error is expressed by:

$$
\begin{gathered}
d c_{i}=E . * \frac{Y_{1 i}}{\sum_{i=1}^{5} Y_{1 i}+Z} \quad d Z=E . * \frac{Y_{1 i}}{\sum_{i=1}^{5} Y_{1 i}+Z} \\
d a_{i 1}=d c_{i} * \frac{X_{i}}{X_{i}+R_{i}} \quad d a_{i 2}=d c_{i} * \frac{R_{i}}{X_{i}+R_{i}} \\
d w_{i j}=d a_{i 2} * \frac{w_{i j}}{\sum_{j=1}^{5} w_{i j}}
\end{gathered}
$$

Weighted adjustment is expressed by:

$$
\begin{array}{r}
w_{i j(\text { new })}=w_{i j(\text { old })}+d w_{i j} * \text { alpha } \\
a_{i 1(\text { new })}=a_{i 1(\text { old })}+d a_{i 1} * \text { alpha } a_{i 2(n e w)} \\
=a_{i 2(\text { old })}+d a_{i 2} * \text { alpha } \\
c_{i(n e w)}=c_{i(\text { old })}+d c_{i} * \text { alpha } Z_{(\text {new })} \\
=Z_{(\text {old })}+d Z * \text { alpha }
\end{array}
$$

Where alpha is the learning parameter.
To stop the iteration process during training, it is necessary to use the target error that is set close to zero. The training process is terminated if $S S E<S S E_{\text {target }}$. The logistic function used is tangent-sigmoid expressed by:

$$
f(x)=\frac{e^{x}-e^{-x}}{e^{x}+e^{-x}}
$$

\subsection{Datasets}

This study is using datasets as shown in Table 1 and 2. To measure the effect of all the independent variables to the

\begin{tabular}{|c|c|c|c|c|c|c|c|}
\hline No. & District/City & $\begin{array}{c}\text { YEAR } \\
(t)\end{array}$ & $\begin{array}{c}\text { Local } \\
\text { Government's } \\
\text { Tax (X1) }\end{array}$ & $\begin{array}{c}\text { Local } \\
\text { Government's } \\
\text { Retribution (X2) }\end{array}$ & $\begin{array}{c}\text { General } \\
\text { Allocation } \\
\text { Fund (X3) }\end{array}$ & $\begin{array}{c}\text { Special } \\
\text { Allocation } \\
\text { Fund (X4) }\end{array}$ & $\begin{array}{c}\text { Revenue } \\
\text { Sharing } \\
\text { Fund (X5) }\end{array}$ \\
\hline 1 & SAMARINDA & 2010 & 24.15786 & 24.04357 & 26.16978 & 23.16826 & 27.15548 \\
\hline 2 & & 2011 & 24.28756 & 23.98326 & 26.30201 & 23.56492 & 26.97937 \\
\hline 3 & & 2012 & 24.49037 & 24.29586 & 26.37104 & 22.82276 & 27.31873 \\
\hline 4 & & 2013 & 24.62133 & 24.51462 & 26.31591 & 23.66977 & 27.19514 \\
\hline 5 & & 2014 & 24.80343 & 24.66025 & 25.92076 & 19.52209 & 27.35946 \\
\hline 6 & & 2015 & 24.96541 & 24.88043 & 25.79507 & 20.04883 & 27.27198 \\
\hline 7 & BALIKPAPAN & 2010 & 24.54454 & 23.85961 & 25.62922 & 23.03780 & 27.20808 \\
\hline 8 & & 2011 & 24.61855 & 23.94650 & 25.91328 & 23.18826 & 27.05967 \\
\hline 9 & & 2012 & 24.90071 & 23.99134 & 25.88456 & 22.75155 & 27.38264 \\
\hline 10 & & 2013 & 25.05676 & 24.04519 & 25.89856 & 24.26689 & 27.11592 \\
\hline 11 & & 2014 & 25.20562 & 24.09345 & 25.06692 & 22.59390 & 27.35797 \\
\hline 12 & & 2015 & 25.27710 & 24.19754 & 24.93795 & 23.32116 & 27.43544 \\
\hline 13 & BONTANG & 2010 & 23.37710 & 21.46658 & 25.13032 & 23.34931 & 27.14527 \\
\hline 14 & & 2011 & 23.40628 & 21.65932 & 24.96327 & 22.39596 & 26.95162 \\
\hline 15 & & 2012 & 23.53099 & 21.90351 & 24.61365 & 22.72339 & 27.28438 \\
\hline 16 & & 2013 & 23.49626 & 22.02800 & 23.52183 & 22.76019 & 27.01582 \\
\hline 17 & & 2014 & 23.43968 & 21.77487 & 22.63894 & 22.67053 & 27.33459 \\
\hline 18 & & 2015 & 23.53415 & 21.96583 & 22.86829 & 22.76019 & 27.19326 \\
\hline 19 & KUKAR & 2010 & 22.78497 & 23.29575 & 26.49978 & 24.61006 & 28.93262 \\
\hline 20 & & 2011 & 21.79480 & 22.91828 & 26.33272 & 21.85163 & 28.55909 \\
\hline 21 & & 2012 & 23.52165 & 23.82061 & 25.16929 & 21.76784 & 28.93070 \\
\hline
\end{tabular}
dependent variable, the Eq. (5) and (6) are need to be modified as follows:

$$
\begin{gathered}
Y_{1}(t+1)=\alpha_{6} X(t)+e_{2} \\
Y_{2}(t+1)=\alpha_{7} X(t)+\alpha_{8} Y_{1}(t)+e_{3}
\end{gathered}
$$

The heuristic network training process is done using programs created using MATLAB tool software.

Table 1. Datasets of the fiscal decentralization in East Kalimantan - Indonesia Period 2010-2015 
International Journal of Engineering and Advanced Technology (IJEAT) ISSN: 2249 - 8958, Volume-8 Issue-5C, May 2019 India

\begin{tabular}{|c|c|c|c|c|c|c|c|}
\hline 22 & & 2013 & 23.33257 & 23.95647 & 25.03344 & 24.37067 & 28.63534 \\
\hline 23 & & 2014 & 23.00496 & 22.90807 & 22.61169 & 22.23821 & 29.03424 \\
\hline 24 & & 2015 & 22.69140 & 22.53174 & 22.36924 & 22.14578 & 29.32423 \\
\hline 25 & KUTAI TIMUR & 2010 & 20.95051 & 21.73793 & 25.91727 & 23.04044 & 27.52285 \\
\hline 26 & & 2011 & 21.55935 & 22.39926 & 26.24782 & 25.61523 & 27.49903 \\
\hline 27 & & 2012 & 22.21076 & 22.98926 & 26.40076 & 26.89158 & 27.81246 \\
\hline 28 & & 2013 & 22.76182 & 22.97356 & 25.94206 & 24.75106 & 27.79700 \\
\hline 29 & & 2014 & 22.28603 & 22.75724 & 24.97457 & 24.61213 & 27.91272 \\
\hline 30 & & 2015 & 22.76182 & 22.15643 & 24.69029 & 24.53168 & 27.80394 \\
\hline 31 & KUTAI BARAT & 2010 & 21.36931 & 22.06838 & 26.35143 & 24.60198 & 27.14488 \\
\hline 32 & & 2011 & 22.02696 & 22.26167 & 26.52832 & 23.67750 & 27.12758 \\
\hline 33 & & 2012 & 22.47229 & 22.89008 & 26.63591 & 24.72612 & 27.31646 \\
\hline 34 & & 2013 & 22.00540 & 22.33456 & 26.55190 & 23.37103 & 27.25226 \\
\hline 35 & & 2014 & 22.78041 & 22.54632 & 26.25367 & 24.52929 & 27.45791 \\
\hline 36 & & 2015 & 22.26835 & 22.79182 & 26.35143 & 24.60198 & 27.29969 \\
\hline 37 & PASER & 2010 & 20.85587 & 22.87078 & 25.48188 & 24.00175 & 27.04934 \\
\hline 38 & & 2011 & 20.92516 & 23.34098 & 25.87753 & 22.62697 & 26.90788 \\
\hline 39 & & 2012 & 21.46868 & 23.47457 & 25.93641 & 22.83155 & 27.29343 \\
\hline 40 & & 2013 & 21.39596 & 23.31125 & 25.56481 & 22.74574 & 27.12964 \\
\hline 41 & & 2014 & 21.99669 & 23.36984 & 23.95235 & 22.21922 & 27.35873 \\
\hline 42 & & 2015 & 20.59704 & 23.11490 & 23.76304 & 23.68646 & 27.19226 \\
\hline 43 & BERAU & 2010 & 22.35371 & 22.45341 & 26.08848 & 24.87772 & 27.03770 \\
\hline 44 & & 2011 & 22.54633 & 22.97917 & 26.41352 & 22.80424 & 26.91673 \\
\hline 45 & & 2012 & 22.57314 & 22.48448 & 26.43967 & 23.15222 & 27.26344 \\
\hline 46 & & 2013 & 22.85764 & 23.47669 & 26.26200 & 23.77020 & 27.01658 \\
\hline 47 & & 2014 & 22.27624 & 23.20982 & 25.80043 & 23.52105 & 27.30024 \\
\hline 48 & & 2015 & 22.11490 & 23.08183 & 25.65005 & 24.22573 & 27.35289 \\
\hline 49 & PPU & 2010 & 20.42262 & 22.11804 & 24.18806 & 24.19040 & 27.13457 \\
\hline 50 & & 2011 & 19.71231 & 21.73920 & 24.68659 & 23.86684 & 26.90869 \\
\hline 51 & & 2012 & 20.00681 & 22.29042 & 24.22256 & 22.28737 & 27.23590 \\
\hline 52 & & 2013 & 20.05336 & 22.18996 & 23.84604 & 23.07009 & 26.94106 \\
\hline 53 & & 2014 & 20.46895 & 21.75195 & 23.62464 & 22.29973 & 27.31196 \\
\hline 54 & & 2015 & 20.53977 & 21.82996 & 24.40796 & 22.22502 & 27.50184 \\
\hline
\end{tabular}


International Journal of Engineering and Advanced Technology (IJEAT) ISSN: 2249 - 8958, Volume-8, Issue-5C, May 2019

Table 2. Datasets of the economic growth and income inequality in East Kalimantan - Indonesia Period 2010-2015

\begin{tabular}{|c|c|c|c|c|c|c|c|}
\hline NO. & District/City & Year $(t)$ & $\begin{array}{c}\text { Economic } \\
\text { Growth (Y1) }\end{array}$ & $\begin{array}{c}\text { Income } \\
\text { Inequality (Y2) }\end{array}$ & $\begin{array}{l}\text { Year } \\
(t+1)\end{array}$ & $\mathrm{Y} 1(t+1)$ & $\mathrm{Y} 2(t+1)$ \\
\hline 1 & SAMARINDA & 2010 & 5.90 & 0.250 & 2011 & 3.11 & 0.249 \\
\hline 2 & & 2011 & 3.11 & 0.249 & 2012 & 4.82 & 0.189 \\
\hline 3 & & 2012 & 4.82 & 0.189 & 2013 & 4.49 & 0.151 \\
\hline 4 & & 2013 & 4.49 & 0.151 & 2014 & 6.30 & 0.110 \\
\hline 5 & & 2014 & 6.30 & 0.110 & 2015 & 6.60 & 0.131 \\
\hline 6 & & 2015 & 6.60 & 0.131 & 2010 & 3.26 & 0.270 \\
\hline 7 & BALIKPAPAN & 2010 & 3.26 & 0.270 & 2011 & 2.08 & 0.186 \\
\hline 8 & & 2011 & 2.08 & 0.186 & 2012 & 12.37 & 0.150 \\
\hline 9 & & 2012 & 12.37 & 0.150 & 2013 & 1.70 & 0.135 \\
\hline 10 & & 2013 & 1.70 & 0.135 & 2014 & 5.13 & 0.140 \\
\hline 11 & & 2014 & 5.13 & 0.140 & 2015 & 7.22 & 0.138 \\
\hline 12 & & 2015 & 7.22 & 0.138 & 2010 & $(2.94)$ & 0.206 \\
\hline 13 & BONTANG & 2010 & $(2.94)$ & 0.206 & 2011 & $(3.97)$ & 0.280 \\
\hline 14 & & 2011 & $(3.97)$ & 0.280 & 2012 & 0.53 & 0.175 \\
\hline 15 & & 2012 & 0.53 & 0.175 & 2013 & $(3.03)$ & 0.194 \\
\hline 16 & & 2013 & (3.03) & 0.194 & 2014 & $(3.44)$ & 0.174 \\
\hline 17 & & 2014 & $(3.44)$ & 0.174 & 2015 & $(7.98)$ & 0.184 \\
\hline 18 & & 2015 & (7.98) & 0.184 & 2010 & $(2.53)$ & 0.240 \\
\hline 19 & KUKAR & 2010 & $(2.53)$ & 0.240 & 2011 & $(4.02)$ & 0.211 \\
\hline 20 & & 2011 & $(4.02)$ & 0.211 & 2012 & 4.67 & 0.249 \\
\hline 21 & & 2012 & 4.67 & 0.249 & 2013 & 2.08 & 0.222 \\
\hline 22 & & 2013 & 2.08 & 0.222 & 2014 & 3.88 & 0.222 \\
\hline 23 & & 2014 & 3.88 & 0.222 & 2015 & 0.25 & 0.222 \\
\hline 24 & & 2015 & 0.25 & 0.222 & 2010 & 22.39 & 0.221 \\
\hline 25 & KUTAI TIMUR & 2010 & 22.39 & 0.221 & 2011 & 8.08 & 0.230 \\
\hline 26 & & 2011 & 8.08 & 0.230 & 2012 & $(0.86)$ & 0.204 \\
\hline 27 & & 2012 & $(0.86)$ & 0.204 & 2013 & 5.60 & 0.235 \\
\hline 28 & & 2013 & 5.60 & 0.235 & 2014 & 9.28 & 0.215 \\
\hline 29 & & 2014 & 9.28 & 0.215 & 2015 & 11.43 & 0.225 \\
\hline 30 & & 2015 & 11.43 & 0.225 & 2010 & 6.11 & 0.254 \\
\hline 31 & KUTAI BARAT & 2010 & 6.11 & 0.254 & 2011 & 6.45 & 0.227 \\
\hline 32 & & 2011 & 6.45 & 0.227 & 2012 & 6.83 & 0.283 \\
\hline 33 & & 2012 & 6.83 & 0.283 & 2013 & 6.89 & 0.266 \\
\hline 34 & & 2013 & 6.89 & 0.266 & 2014 & 6.10 & 0.242 \\
\hline 35 & & 2014 & 6.10 & 0.242 & 2015 & 7.85 & 0.254 \\
\hline
\end{tabular}


International Journal of Engineering and Advanced Technology (IJEAT)

ISSN: 2249 - 8958, Volume-8 Issue-5C, May 2019 India

\begin{tabular}{|c|c|c|c|c|c|c|c|}
\hline 36 & & 2015 & 7.85 & 0.254 & 2010 & 1.94 & 0.330 \\
\hline 37 & PASER & 2010 & 11.94 & 0.330 & 2011 & 12.92 & 0.319 \\
\hline 38 & & 2011 & 12.92 & 0.319 & 2012 & 7.10 & 0.283 \\
\hline 39 & & 2012 & 7.10 & 0.283 & 2013 & 7.74 & 0.266 \\
\hline 40 & & 2013 & 7.74 & 0.266 & 2014 & 17.31 & 0.242 \\
\hline 41 & & 2014 & 17.31 & 0.242 & 2015 & 10.85 & 0.254 \\
\hline 42 & & 2015 & 10.85 & 0.254 & 2010 & 5.08 & 0.260 \\
\hline 43 & BERAU & 2010 & 5.08 & 0.260 & 2011 & 5.70 & 0.247 \\
\hline 44 & & 2011 & 5.70 & 0.247 & 2012 & 4.97 & 0.219 \\
\hline 45 & & 2012 & 4.97 & 0.219 & 2013 & 10.57 & 0.186 \\
\hline 46 & & 2013 & 10.57 & 0.186 & 2014 & 8.03 & 0.180 \\
\hline 47 & & 2014 & 8.03 & 0.180 & 2015 & 7.93 & 0.183 \\
\hline 48 & & 2015 & 7.93 & 0.183 & 2010 & 1.63 & 0.246 \\
\hline 49 & PPU & 2010 & 1.63 & 0.246 & 2011 & 3.79 & 0.284 \\
\hline 50 & & 2011 & 3.79 & 0.284 & 2012 & 4.99 & 0.245 \\
\hline 51 & & 2012 & 4.99 & 0.245 & 2013 & 3.51 & 0.229 \\
\hline 52 & & 2013 & 3.51 & 0.229 & 2014 & 7.28 & 0.225 \\
\hline 53 & & 2014 & 7.28 & 0.225 & 2015 & 11.68 & 0.227 \\
\hline 54 & & 2015 & 11.68 & 0.227 & & & \\
\hline
\end{tabular}

III. RESULT AND DISCUSSION

There are two heuristic networks to be trained based on Eq. (21) and (22) by using all the data in Table 1 and 2 . The SSE target used in the training process is 0.001 , learning parameter used is alpha $=0.5$, and all the weight initialization are set to 0.0001 . The performances of training errors during the training process are shown in Fig. 3 and 4. All the final weights of heuristic network are shown in Table 3 and 4.

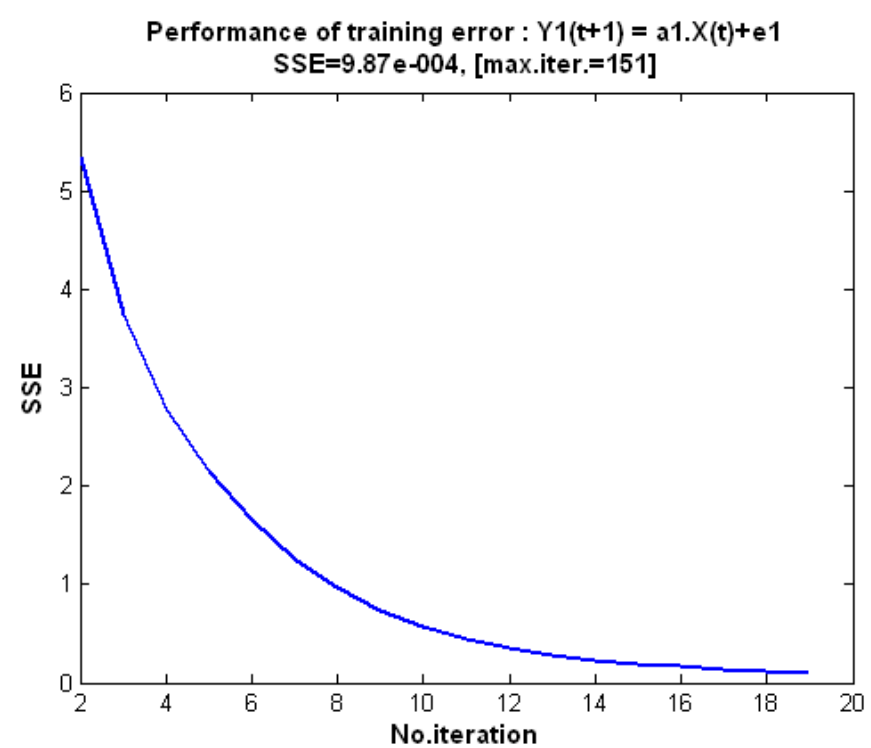

Figure 3. Training error performance of Heuristic Network 1 (Eq. (21))

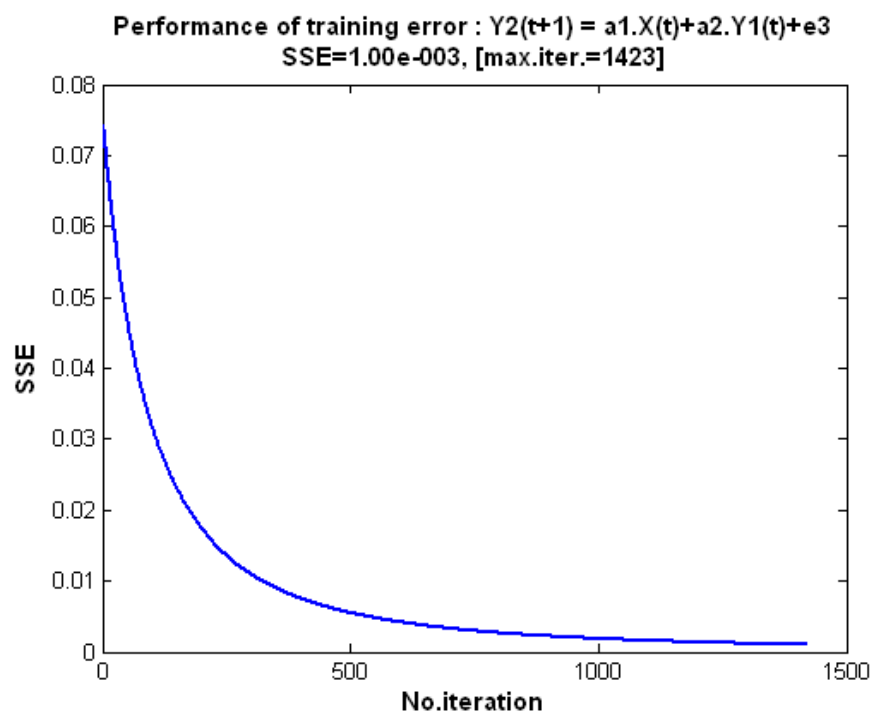

Figure 4. Training error performance of Heuristic Network 1 (Eq. (22)) 
Table 3. Final weight of Heuristic Network 1

\begin{tabular}{|c|c|c|c|}
\hline $\begin{array}{c}\text { Varia } \\
\text { bles }\end{array}$ & $\begin{array}{c}\text { Partial } \\
\text { coefficient } \\
a_{11} \ldots a_{51}\end{array}$ & $\begin{array}{c}\text { Coefficient of residual } \\
\text { correlation } \\
a_{12} \ldots a_{52}\end{array}$ & $\begin{array}{c}\text { Main } \\
\text { coefficient } \\
c_{1} \ldots c_{5}\end{array}$ \\
\hline$X 1$ & 0.53251 & 0.000433 & 0.53284 \\
\hline$X 2$ & 0.53254 & 0.000403 & 0.53284 \\
\hline$X 3$ & 0.53258 & 0.000366 & 0.53284 \\
\hline$X 4$ & 0.53255 & 0.000391 & 0.53284 \\
\hline$X 5$ & 0.53263 & 0.000311 & 0.53284 \\
\hline
\end{tabular}

Table 4. Final weight of Heuristic Network 2

\begin{tabular}{|c|c|c|c|}
\hline $\begin{array}{c}\text { Varia } \\
\text { bles }\end{array}$ & $\begin{array}{c}\text { Partial } \\
\text { coefficient } \\
a_{11} \ldots a_{51}\end{array}$ & $\begin{array}{c}\text { Coefficient of residual } \\
\text { correlation } \\
a_{12} \ldots a_{52}\end{array}$ & $\begin{array}{c}\text { Main } \\
\text { coefficient } \\
c_{1} \ldots c_{5}\end{array}$ \\
\hline$X 1$ & -0.00042 & $9.98 \mathrm{E}-05$ & -0.00042 \\
\hline$X 2$ & -0.00042 & $9.98 \mathrm{E}-05$ & -0.00042 \\
\hline$X 3$ & -0.00042 & $9.98 \mathrm{E}-05$ & -0.00042 \\
\hline$X 4$ & -0.00042 & $9.98 \mathrm{E}-05$ & -0.00042 \\
\hline$X 5$ & -0.00042 & $9.98 \mathrm{E}-05$ & -0.00042 \\
\hline$Y 1$ & -0.00034 & $9.98 \mathrm{E}-05$ & -0.00034 \\
\hline
\end{tabular}

From Table 3 and 4 it can be found that all coefficients of residual correlation are small enough so that it can be said that all input variables are proved independent. Because all the main coefficients from Table 3 are positive so that it can be said that fiscal decentralization $(X)$ gives a direct influence on economic growth $(Y 1)$ by the average of 0.53 . While all the main coefficients from Table 4 are negative both $X$ and $Y 1$. It can be said that the fiscal decentralization directly gives a negative influence on income inequality by the average of -0.00042 , and indirectly gives a negative influence through economic growth on the average of 0.00034 . With the value of the main coefficient is small enough it can be concluded that fiscal decentralization does not give any effect to income inequality.

\section{CONCLUSION}

In this paper, the heuristic network has been used to measure the impact of fiscal decentralization on economic growth and income inequality. After the training process, all residual correlation coefficients are obtained quite small. This proves that all input variables are independent. The analysis of all main coefficients concludes that fiscal decentralization does not give any effect on income inequality. In this case, the hypothesis that has been made is proven. To prove the accuracy of the conclusions that have been made, the future work is how to measure the impact of income inequality on economic growth and fiscal decentralization.

\section{ACKNOWLEDGMENTS}

The authors would like to express their heartfelt thanks to The Modern Computing Research Center, Department of Information Technology, State Polytechnic of Samarinda for providing all their support.

\section{REFERENCES}

1. D. Tirtosuharto, Does fiscal decentralization help Indonesia avoid the middle-income trap ?, ADBI Working Paper 729. Tokyo:Asian Development Bank Institute, Japan, 2017.

2. M. Miri, E. H. Taacha, and M. A. Benatia, "Fiscal Decentralization and Economic Growth in Morocco: A Panel Cointegration Analysis," International Journal of Economics and Financial Issues, vol. 7, no. 6, pp. 192201, 2017.

3. T. H. Simanjuntak, and I. Mukhlis, "The Relation of Fiscal Decentralization, Regional Finance and Social Justice for the Local Development of Indonesia," Applied Economics and Finance, vol. 4, no. 1, 2016.

4. U. Arif, and E. Ahmad, "Growth Effects of Fiscal Decentralization: The Role of Macroeconomic Stability and Governance Institutions," FWU Journal of Social Sciences, vol. 11, no. 1, pp. 276-289, 2017.

5. A. Fye, "Significance of fiscal decentralisation: The Gambia at a glance," Net Journal of Business Management, vol. 5, no. 1, pp. 6-18, 2017.

6. E. Wicaksono, H. Amir, and A. Nugroho, "The sources of income inequality in Indonesia: A Regression-based inequality decomposition," ADBI Working Paper 667. Tokyo: Asian Development Bank Institute, 2017.

7. K. H. Park, Education, globalization, and income inequality in Asia, ADBI Working Paper 732. Tokyo: Asian Development Bank Institute., Japan, 2017.

8. S. R. Basu, "Do data show divergence ? Revisiting global income inequalitiy trends," Asia-Pacific Development Journal, vol. 24, no. 1, pp. 23-53, 2017.

9. A. Bojanic, "The Impact of Fiscal Decentralization on Accountability, Economic Freedom, and Political and Civil Liberties in the Americas," Economies, vol. 6, no. 1, pp. 8, 2018.

10. S. Makreshanska, and G. Petrevski, Decentralization, scal transfers and income inequality in Central and Eastern European countries, Skopje, 2016.

11. R. Islam, A. B. A. Ghani, r. Z. Abidin et al., "Impact on poverty and income inequality in Malaysia's economic growth," Problems and Perspectives in Management, vol. 15, no. 1, pp. 55-62, 2017.

12. C. F. Sepulveda, and J. Martinez-Vasquez, "The consequences of fiscal decentralization on poverty and income equality," Environmental and Planning C: Government and Policy, vol. 29, pp. 321-343, 2011.

13. L. Magnani, Heuristic Reasoning: Springer International Publishing Switzerland, 2015.

14. M. B. Ridha, "The Role of Heuristic Methods as a Decision-Making Tool in Aggregate Production Planning," International Journal of Business Administration, vol. 6, no. 2, 2015. 